\title{
Psychology and Law, Meet Open Science
}

\author{
Bradley D. McAuliff \\ California State University, Northridge
}

Melanie B. Fessinger

Graduate Center and John Jay College of Criminal Justice

City University of New York

Anthony D. Perillo
Indiana University of Pennsylvania

Jennifer T. Perillo

Indiana University of Pennsylvania

Chapter to appear in The Oxford Handbook of Psychology and Law

D. DeMatteo \& K. C. Scherr (Eds.)

Version accepted for print on September 18, 2021

Questions or inquiries may be directed to bradley.mcauliff@csun.edu 


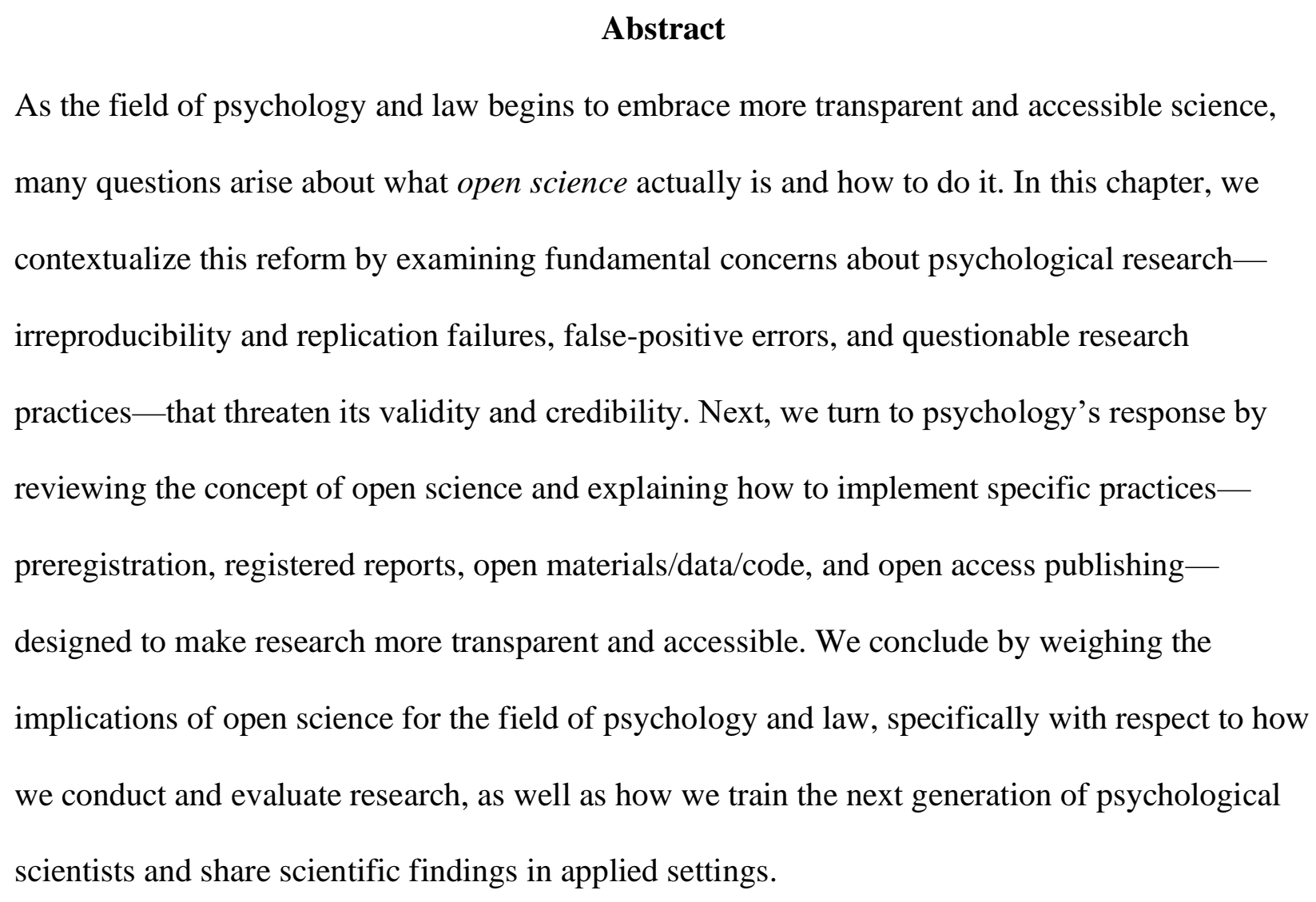

As the field of psychology and law begins to embrace more transparent and accessible science, many questions arise about what open science actually is and how to do it. In this chapter, we contextualize this reform by examining fundamental concerns about psychological researchirreproducibility and replication failures, false-positive errors, and questionable research practices - that threaten its validity and credibility. Next, we turn to psychology's response by reviewing the concept of open science and explaining how to implement specific practicespreregistration, registered reports, open materials/data/code, and open access publishingdesigned to make research more transparent and accessible. We conclude by weighing the implications of open science for the field of psychology and law, specifically with respect to how we conduct and evaluate research, as well as how we train the next generation of psychological scientists and share scientific findings in applied settings. 
OPEN SCIENCE IN PSYCHOLOGY AND LAW RESEARCH 3

\section{Psychology and Law, Meet Open Science}

Psychological science is experiencing a fundamental paradigm shift. Whether characterized as a "crisis of confidence" (Pashler \& Wagenmakers, 2012, p. 528), a "credibility revolution” (Vazire, 2018, p. 411), or “psychology’s renaissance” (Nelson et al., 2018, p. 512), how researchers design, conduct, and report their work has changed dramatically in recent times. This transformation is perhaps best described as an unprecedented emphasis on transparency and accessibility. We have begun to lift the shroud of scientific discovery to evaluate the underlying processes and decisions themselves, from theory and prediction to design, measurement, and execution to analysis and conclusions. Now more than ever, it is clear that the value of psychological science depends on the integrity of those underlying processes and decisions, which should be in plain view for all to see.

The subdiscipline of psychology and law has not been exempt from this trend. The Executive Committee of the American Psychology-Law Society (AP-LS; Division 41 of the American Psychological Association) voted unanimously in March 2017 for its flagship journal Law and Human Behavior to become a formal signatory of the Transparency and Openness Promotion (TOP) guidelines. That same year, Editor-in-Chief Margaret Bull Kovera introduced Open Science Badges in an effort to recognize and incentivize the public sharing of data, materials, pre-registration plans, and analyses. In 2018, 19\% of the articles published in Law and Human Behavior qualified for at least one badge and by the end of 2020 that number rose to 28\%. In 2019, Editor-in-Chief Bradley McAuliff implemented the journal's first phase of the TOP Guidelines focusing on the transparency of data, design, and materials (McAuliff et al., 2019), and in 2020 the journal began accepting proposals for registered reports. Extrapolating from these milestones and recent editorials in other psychology and law journals (Lamb et al., 
2021; Neuschatz, 2020), there is a growing expectation for transparent and accessible science in psychology and law.

The purpose of this chapter is to explain open science and contemplate what it means for the field of psychology and law. We begin by contextualizing the recent paradigm shift by focusing on its genesis in irreproducibility and replication failures, false-positive errors, and questionable research practices. Next, we turn to psychology's response by reviewing the open science movement and common practices that include preregistration, registered reports, open materials, open data and code, and open access publishing. We conclude by weighing the implications of open science for the field of psychology and law, specifically with respect to how we conduct and evaluate research, as well as how we train the next generation of psychological scientists and share our findings in applied settings.

\section{How Did We Get Here?}

Scholars point to a series of events involving irreproducibility and replication failures, false-positive errors, and questionable research practices that have catalyzed the open science movement (Nelson et al., 2018; Tackett et al., 2019).

\section{Irreproducibility and Replication Failures}

Recent research has revealed that most, but certainly not all, published psychological science is reproducible (see Artner et al., 2020, Table 1, for a list of published reproducibility research in psychology as of August 2020). By reproducible, we mean that an independent researcher obtained identical results as the original researcher using the same data and analyses (NAS, 2019). Across three studies that examined the reproducibility of articles appearing in prominent psychology journals, the majority of primary claims (between $60 \%$ and $70 \%$ ) were, in fact, reproducible (Artner et al., 2020; Hardwicke et al., 2018, 2021). However, the ability to 
reproduce findings often required consulting with the authors and receiving additional data or code because the original articles tended to report unclear, incomplete, or incorrect descriptions of data analytic procedures (Hardwicke et al., 2018). Moreover, although the majority of primary claims were reproducible, a notable proportion of claims were not (between $30 \%$ and $40 \%$ ).

These initial empirical investigations reveal a mixed picture of reproducibility. It is reassuring that the statistics for most primary claims in published psychological research were reproducible. And when errors occurred, they generally did not affect the authors' original conclusions. Yet we must also consider the potential role of selection bias in yielding an overly optimistic assessment of reproducibility. All three studies examined articles for which authors made original data openly available - a practice that is increasingly common, but not yet the norm. Errors may be more common in data that authors are unwilling to share. The research teams also focused on relatively basic statistics (e.g., regression, t-tests, ANOVAs), but reproducibility of more complicated analyses (e.g., linear regression, structural equation modeling) has proven difficult in other fields (Bergh et al., 2017). Perhaps most importantly, any attempt to evaluate reproducibility using original data is only as good as the information authors provide about key decisions, such as operationalizing variables and analyzing results. In this respect, "vagueness makes assessing reproducibility a nightmare" (Artner et al., 2020, p. 12) and we all must strive to ensure those attempting to reproduce results get a good night's sleep.

Extending beyond pure reproducibility, researchers have also begun to question the replicability of published findings. By replicability, we mean that researchers obtain the same general result across different samples and studies that vary fundamental components of the research design, such as the experimental manipulations, operational definitions, and procedures (Asendorpf et al., 2013). Reproducibility is an absolute judgment (original data + same analyses 
= identical result ?), while replication is a matter of degree because it entails research design variations. It is difficult to answer the question of how replicable psychological research truly is (Maxwell et al., 2015), and scientists disagree about what level of replicability we should expect (Gordon et al., 2021). Consider, for example, the effects of interviewer rapport on witness accuracy. There are myriad ways researchers can operationalize rapport and measure accuracy, so it is unrealistic to expect different studies will yield truly identical results. However, we can establish replicability by observing that, across different studies, the same general result emerges: interviewers' provision of rapport (however operationalized) increases witness accuracy (however measured). But how do we determine whether "the same general result emerges"? We can look at the pattern of statistical significance across studies, whether they agree about the direction of the effects, and/or whether the effect sizes of subsequent studies fall within the confidence interval of the original study (Valentine et al., 2011). How we choose to operationalize "replicability" will affect whether we conclude that results are, in fact, replicable.

Scholars have sought to quantify the replicability of psychological science despite the inherent challenges. In the largest systematic examination of replication studies to date, Nosek and colleagues (2021) amassed evidence from both "systematic replications" that conducted as many studies in a defined sampling frame as possible and "multi-site replications" that conducted the same replication protocol in a variety of samples and settings. Across an impressive total of 307 replications, $64 \%$ reported statistically significant results in the same direction as the original studies with effect sizes that were $68 \%$ as large. Thus, the existing data suggest that the replication rates in psychological science are similar to those observed in reproducibility studies. It is encouraging that most effects replicated using two common types of replications. However, sample sizes for the replication studies were much larger than those from 
original studies, which resulted in more precise estimates of effect size and heterogeneity, but also led to a "relatively generous definition of success" due to increased statistical power to detect significant differences in the same direction as the original effects (Nosek et al., 2021, p. 9). In other words, these findings are vexing because a larger number of lower-powered original studies detected differences compared to a smaller number of higher-powered replication studies. False-positive errors and questionable research practices likely contribute to this paradox in psychology's published literature.

\section{False-Positive Errors and Questionable Research Practices}

For decades, the scientific community has largely ignored several inconvenient truths about published psychological research. First, most studies are woefully underpowered, meaning their ability to detect true differences between groups is extremely low (Cohen, 1962; Sedlmeier

\& Gigerenzer, 1989). Second, psychological phenomena are complex and multidetermined (Gotz et al., 2021), and the effect of any single factor is typically small to medium in size (Lovakov \& Agadullina, 2021). Third, despite the prevalence of underpowered studies and elusive effects, the rate at which studies in journals report detecting differences between groups is exceedingly high, even as high as $96 \%$ (Scheel et al., 2021). This reality implicates the presence of false-positive errors in which researchers mistakenly conclude an effect or difference between groups exists when it does not (i.e., Type 1 error). False-positive errors are even more likely to occur when testing hypotheses with a lower prior probability of being true (Nosek et al., 2021), and one study calculated an average prior probability of just .088 (9\%) across 44 articles published in three top psychology journals (Dreber et al., 2015).

Ioannidis (2005) was among the first to formally sound the alarm with his article titled "Why Most Published Research Findings Are False." He argued that the combination of various 
design, data analysis, and presentation factors (collectively termed "bias") tends to produce falsepositive research findings. Bias can manifest in several study characteristics that increase the likelihood a result is not true, such as small sample size, small effect sizes, testing a large number of relationships that were not preselected, and using flexible designs, definitions, outcomes, and analyses. Simmons and colleagues (2011) escalated these concerns by demonstrating how unacceptably easy it is to obtain statistically significant evidence for a false hypothesis (in that study, testing the ability of certain songs to change listeners' ages). Like Ioannidis, they were troubled by potential bias and focused on "researcher degrees of freedom," referring to the relatively unfettered flexibility researchers have when making data collection and analysis decisions:

Should some observations be excluded? Which conditions should be combined and which ones compared? Which control variables should be considered? Should specific measures be combined or transformed or both? (Simmons et al., p. 1359)

Using computer simulations of experimental data, Simmons and colleagues established that four common researcher degrees of freedom are particularly pernicious in producing false-positives: selectively reporting dependent variables, using interim data analyses to determine stopping points for data collection and sample size, including covariates, and reporting subsets of experimental conditions. The combination of all four practices increased the likelihood of obtaining a false-positive result from the conventional 5\% (alpha) to $61 \%$ in their simulations.

How frequently do researcher degrees of freedom lead to questionable research practices (QRPs) in the published psychological literature? Nosek at colleagues (2021) analyzed 14 QRP surveys of psychology researchers worldwide and observed that $78 \%$ of those surveyed reported engaging in at least one of these practices in their own research. See Table 1 for specific examples of QRPs. Almost half of researchers admitted to selectively reporting studies that 
"worked" (48\%), failing to report all dependent variables (46\%), and deciding whether to collect additional data after examining whether results were statistically significant (40\%). Roughly onethird of researchers reported hypothesizing after the results were known ("HARKing", 36\%) and excluding data after examining its effect on the results (32\%), and nearly one-quarter failed to report all study conditions $(23 \%)$ and rounded $p$ values to meet a prespecified threshold (21\%). Far fewer reported stopping data collection earlier than planned after obtaining the expected result $(12 \%)$, claiming results were unaffected by demographic variables such as gender when uncertain (3\%), and falsifying data (2\%). Although these rates are likely to be influenced by selfserving bias and respondents' limited insight into their own decisions and behaviors, the high proportion of researchers admitting to engaging in QRPs is troubling.

More objective measures show that QRPs are quite prevalent. Franco and colleagues (2016) compared original study registrations to final published manuscripts and found that $41 \%$ of manuscripts failed to report all experimental conditions and $72 \%$ reported fewer outcome variables than what appeared on a public study registry. Moreover, reported effect sizes were twice as large and nearly three times as likely to be significant than unreported effects. In published social psychology dissertations, Cairo et al. (2020) found that nearly one-third (32\%) of the original hypotheses were dropped from the manuscripts. Authors were more likely to drop unsupported hypotheses and maintain fully- or partially-supported hypotheses. Additionally, nearly half (48\%) of manuscripts showed evidence of other questionable (or "selective") research practices, including changing sample size (20\%) and dropping variables (18\%).

Both self-report and publication pipeline studies reveal that QRPs are common in the field of psychology. Though rates for specific practices are generally low, most psychological researchers admit to engaging in at least one QRP in their own research. In fact, some of the 
most frequently reported and observed infractions represent three of the four researcher degrees of freedom shown to dramatically increase false-positive errors (failing to report dependent variables, reporting only a subset of experimental conditions, and collecting additional data after examining statistical significance), especially when combined (Simmons et al., 2011).

The question of whether recent research findings on reproducibility, replicability, falsepositive errors, and QRPs is symptomatic of a science that is "rotten to the core" or "not so bad" (Motyl et al., 2017, p. 36) remains open to healthy scholarly debate and empirical investigation. For certain, this growing body of findings has revealed that published psychological studiesmuch like the scientists behind them - are imperfect. Be that as it may, the stark reality is that failures to replicate impede the acquisition of knowledge, distort the truth, waste valuable resources, and can result in decisions and policies that are ineffective or even harmful (Nelson et al., 2018; Tackett et al., 2019). Suffice to say, we can do better as a discipline to improve the rigor and transparency of psychological science.

\section{What is Open Science?}

Even though many scientists perceive transparency as a normative part of the research process (Anderson et al., 2007), recent concerns about reproducibility, replicability, and falsepositive errors have called into question whether science is as open as it aspires to be (Open Science Collaboration, 2015). As one scholar aptly analogized, scientific reporting is a bit like selling a used car (Vazire, 2017). The researcher, as the salesperson, knows much more about their product than does the reader, as the consumer. The researcher knows the original hypotheses, how many unsuccessful studies were left out of the manuscript, what the raw data look like, and how many analyses were attempted. Without transparent reporting of this information, "it is difficult to tell a cherry from a lemon" (Linsday, 2017, p. 701). Researchers 
OPEN SCIENCE IN PSYCHOLOGY AND LAW RESEARCH 11

have responded to these concerns by calling for a radical shift in the way that science is produced and reported, commonly known as the open science movement (Klein et al., 2018; Nosek et al., 2015; Vazire, 2017).

Open science reflects the idea that scientists should produce and report knowledge in a transparent and accessible manner. These concepts are admittedly abstract because open science itself is an umbrella term; it describes many different practices and, as some have rightly noted, has no formal definition (Arabito \& Pitrelli, 2015). This ambiguity has led to the development of several schools of thought on the purpose and goals of the movement, but they tend to converge around the same basic goals: to strengthen and accelerate scientific progress, to enhance the accessibility of scientific work, to increase representativeness and access within science, and to improve trust in the institution of science (Ledgerwood et al., in press; Masuzzo \& Martens, 2017; Roberts et al., 2020).

One challenge confronting the open science movement is the lack of strong incentives for researchers to be more transparent about their work (Nosek et al., 2012, 2015). The increased time needed to engage in open science practices understandably concerns some researchers. Some open science practices can increase efficiency at other stages of research (e.g., preregistration can establish data analysis rules researchers no longer have to contemplate after collecting data, preprints allow researchers to share findings with others more quickly). Admittedly, though, open science practices require researchers to invest more time and effort into their work at most stages. Issues of time particularly affect students and early career researchers, whose research output risks being judged by admissions, search, and promotion-andtenure committees through traditional metrics (e.g., publications) without credit for additional accomplishments (e.g., preregistrations). These practices can also expose research, and 
researchers themselves, to a higher degree of scrutiny. In recognition of these barriers, a collection of various stakeholders worked together to draft a set of standards that can be adopted by journals and granting agencies to encourage open practices known as the Transparency and Openness Promotion (TOP) Guidelines (Nosek et al., 2015).

The TOP guidelines consist of eight standards regarding citation, design and analysis, materials and methods, data sharing, preregistration, and replication that journals and granting agencies should recommend or require for publication or funding. In the few years since the creation of the TOP Guidelines, hundreds of journals across various disciplines have incorporated the standards into their policies (Mayo-Wilson et al., 2021). Additionally, many journals, including Law and Human Behavior, also encourage and incentivize researchers to participate in open science practices by offering badges to those who do (Kidwell et al., 2016; McAuliff et al., 2019). Those who meet the requirements for a badge receive a badge(s) at the top of their published paper signaling to readers that the researchers participated in one or more open science practices. Some data suggest that the use of badges has led to an increase in open science practices (Kidwell et al., 2016) and trust in research among non-scientists (Schneider et al., 2020).

Many different practices fall under the umbrella of open science. In the sections that follow, we discuss preregistration, registered reports, open materials, open data and code, and open access publishing.

\section{Preregistration}

Preregistration involves documenting a research plan before conducting a study. The research plan often includes a description of the a priori hypotheses, methodology, and analytic plan. It can also include more detail, such as possible competing hypotheses, anticipated data 
transformations, analysis code, and coding schemes. Researchers have flexibility in how much information they include in their preregistrations; however, more detailed preregistration plans can lead to more confidence in the later interpretation of results (Lindsay et al., 2016).

Researchers who choose to preregister their study can use one of several available templates (e.g., van 't Veer \& Giner-Sorolla, 2016; see Table 2 for template links) or draft one themselves.

Researchers typically submit their preregistrations to an external repository such as the Open Science Framework (osf.io) or AsPredicted (aspredicted.org). These repositories allow researchers to make their preregistration publicly accessible for others to verify whether they followed or deviated from their plan. Importantly, researchers have the option of making their preregistration immediately available or entering it into an embargo period during which it is only visible to the researchers or anyone with whom they shared a link (e.g., peer reviewers) until they end the embargo or a predetermined amount of time has passed. The embargo period precludes others from seeing a preregistration, which can mitigate concerns about others "scooping" a project before the researchers have finished it. Once viewable to others, the previously embargoed preregistration documents all the a priori study information as well as a timestamp of when the pregregistration was submitted.

Preregistration is becoming an increasingly popular open science practice (Nosek \& Lindsay, 2018), with many journals incentivizing (Eich, 2014) or requiring registered plans (Jonas \& Cesario, 2015). Proponents of preregistration argue that it will increase the credibility and replicability of findings by decreasing the influence of motivation and biases on data analysis and interpretation (Nosek et al., 2018; van 't Veer \& Giner-Sorolla, 2016). It also has other benefits, such as placing an emphasis on strong theory to guide hypotheses, decreasing HARKing, and reducing reporting biases. In fact, some preliminary data show that having 
\begin{tabular}{ll}
\hline OPEN SCIENCE IN PSYCHOLOGY AND LAW RESEARCH & 14
\end{tabular}

specific a priori hypotheses is related to increased replicability (Swaen et al., 2001) and that preregistration is related to a decrease in positive results (Kaplan \& Irvine, 2015). Thus, preregistration is one tool that can help mitigate the prevalence of QRPs. Researchers seem to be increasingly willing to preregister their studies and some anticipate that it may soon become the norm (Nosek \& Lindsay, 2018).

Other researchers express concerns about preregistration (Goldin-Meadow, 2016). Some are concerned that preregistration takes additional time and effort not worth spending. Indeed, preregistration does require more time and effort of researchers at the beginning of a project. Yet, much of the information that goes into a research plan may be already written for a grant proposal or will eventually have to be written for a manuscript. Moreover, decisions made when preparing a preregistration can save considerable time that would be spent later in the research process, such as how to analyze the data. Therefore, it does not necessarily require much more time than what would have to be spent at some other point in the research process; it merely shifts the time commitment earlier.

Some researchers contend that preregistration is inflexible, not allowing them to make necessary adjustments to their plan or conduct exploratory analyses. This is not the case. Researchers can still make necessary adjustments to their preregistered plans or do exploratory data analyses so long as they are transparent about doing so, which allows others to assess the impact of those changes and analyses on the results (Nosek et al., 2018). In that way, the preregistration serves to make a clear distinction between decisions and inferences that were independent from or dependent on the data (Nosek et al., 2018). Finally, some express concerns that preregistration does not work for all types of research. Importantly, preregistration is certainly not a one-size-fits-all approach. Researchers can include as few or as many details in 
\begin{tabular}{ll}
\hline OPEN SCIENCE IN PSYCHOLOGY AND LAW RESEARCH & 15
\end{tabular}

their preregistrations as they wish; they have various templates to choose from or can create one themselves if existing templates do not fit their study design. In fact, researchers analyzing archival data or conducting secondary data analysis can still preregister their studies; many templates allow researchers to document the state of their data at the time of preregistration (already collected but not analyzed, analyzed for other purposes, etc.). In these ways, preregistration is flexible enough to be a viable option for most types of research (van 't Veer \& Giner-Sorrolla, 2016).

\section{Registered Reports}

Registered reports are an open science practice similar to preregistration but different in that they involve submitting the research plan to the peer review process before data collection has begun. Instead of a full manuscript, reviewers read and assess the research question, hypotheses, sample size, planned methodology, and analysis plan. Pilot testing may be necessary to establish that the manipulations are perceived as intended, and authors must confirm that an institutional review board has approved the proposed research. If the reviewers decide that the research question has the potential to advance the field regardless of the results and that the method is sufficiently strong to address such a question, the journal may grant the authors an "inprinciple acceptance" on the final manuscript (Nosek et al., 2018). This acceptance means that if the researchers execute the study according to their articulated plan and submit a final manuscript to the journal, it will be published regardless of the specific outcomes observed.

Journal editors and reviewers evaluate registered reports based on the quality of the method and execution rather than on the size and direction of their findings.

Like preregistration, registered reports are becoming increasingly more common (Chambers, 2019). Many journals, including Law and Human Behavior and Legal and 
OPEN SCIENCE IN PSYCHOLOGY AND LAW RESEARCH 16

Criminological Psychology, have adopted this new publishing format. Proponents argue that registered reports will decrease publication bias and increase objectivity by masking outcomes during review (Chambers \& Tzavella, 2020; Nosek \& Lakens, 2014). This process encourages reviewers to judge a project purely through its means, not the end results. Registered reports can also decrease the motivation to $p$-hack or to selectively report results because the authors are free to present the results the way that they are rather than having to carve out one clear but perhaps incomplete or inaccurate narrative (Chambers, 2019). Indeed, preliminary evidence shows that registered reports more often contain null results than traditional articles (Allen \& Mehler, 2019). Although this may cause concerns about an eventual "null literature" with decreased journal impact factors and citation counts, some evidence suggests that registered reports receive similar or sometimes even more citations than their traditional counterparts (Hummer et al., 2017) and they may be more reproducible than traditional articles (Chambers \& Tzavella, 2020). Registered reports can also benefit researchers who receive reviewer feedback before devoting their valuable resources to conducting a study. They can incorporate feedback to make revisions to the protocol that may otherwise have led reviewers to reject the final manuscript had it not been vetted up front.

As with all new innovations, there are still concerns about registered reports that must be resolved as the format evolves. Some of these concerns center on how to prepare a registered report itself. For example, what are researchers to do if, lacking a theoretical basis to anticipate potential effect sizes, they cannot reasonably anticipate the number of participants they will need for proper analysis? Other concerns involve how strictly binding an accepted registered report should be and what to do if the completed research deviates from what was registered. Zero leniency could prove detrimental to those whose institutional review boards require protocol 
changes to a registered study, and questions remain as to how reviewers should evaluate the merit of deviating from a registered plan. A lack of consensus on whether in-principle acceptances should include an "expiration date" (i.e., deadlines for submitting the completed study) must also be resolved. Chambers et al. (2014) offer a thorough overview and response to these concerns and several others. Even with many issues still to be resolved, registered reports serve as another tool researchers can use to work toward a more credible and reproducible literature.

\section{Open Materials}

Another open science practice is publicly sharing materials from a research project. Due to space constraints, both formal (e.g., journal page limits) and informal (e.g., reviewer expectations that a paper flow clearly and concisely), authors often omit details and contextual information from their manuscripts that are often important for understanding why a certain study produced certain results (Bowman \& Spence, 2020). It is fairly common to see only a few sample dependent measures, a summary of manipulations, or an overview of the instructions given to participants. Yet many of these details are important to understanding and even replicating the results of study. As decades of research have shown, the exact wording of a question can have a profound impact on the way participants respond (Schwarz, 1999; Tversky \& Kahneman, 1986). We also know that the exact order in which materials are presented to participants can affect their responses (Strack, 1992). These small but impactful details may be left out for the sake of space when authors describe their materials, but are essential to evaluating the results of a study. Open materials allow readers to better evaluate whether the results may be a function of the specific question wording, the instructions given to participants, or the way the 
data were coded. They can also facilitate replications in a manner that would be otherwise difficult if only relying on a summary.

Researchers who share their materials have many options available to them in terms of how and where to do it. They can choose to make their materials publicly available (the purest form of "open"), available to other researchers, or available only by request (Gilmore et al., 2018). They can do so on individual lab websites, through supplemental materials to their manuscript with the publisher, or using external repositories (e.g., Open Science Framework). Different projects have different implications for sharing; therefore, researchers who share their materials need to assess the appropriate level of and venue for doing so. If materials include components that could be used to identify participants (e.g., video-recordings of experimental sessions), researchers need to ensure that they have approval to share through their institutional review boards and consent to do so from participants if applicable. Researchers must curate shared materials so they are easily accessible and understood by others (Wilkinson et al., 2016).

\section{Open Data and Code}

A similar open science practice is publicly sharing the data and code from a research project. Authors often must choose which statistical results are important to include in their manuscript and omit others. Manuscripts typically only contain basic descriptive statistics, tests with significant results, or examples of open-ended data (Bowman \& Spence, 2020). Readers may have questions about the data and analyses that go unanswered without access to the complete data and code, such as what may have happened if the authors chose a different statistical technique or coded their data differently (West, 2016). Access to the data and code enables others outside the research team to check for errors, attempt to reproduce the results, examine how the analytical decisions may have affected the results, assess the inferences the 
OPEN SCIENCE IN PSYCHOLOGY AND LAW RESEARCH 19

authors drew from their results, and in some cases conduct secondary analyses on the data to answer new questions (Gilmore et al., 2018; Lindsay, 2017; West, 2016). They can also use the data in meta-analytic work, which can ultimately lead to more confidence in an observed effect (Lindsay, 2017).

Open data has long been the practice in certain fields (MacWhinney \& Snow, 1985), but is certainly not the norm in others. However, sharing data is becoming more common due to replication concerns. Many journals (e.g., Law and Human Behavior; Psychology, Public Policy, and Law; Legal and Criminological Psychology) and funding agencies (e.g., National Science Foundation, National Institutes of Health) in the United States and abroad (see Borgerud \& Borglund, 2020) strongly recommend or even require that researchers share their data.

Researchers must ensure their shared data and code are findable, accessible, interoperable, and reusable (FAIR; Wilkinson et al., 2016). As with sharing materials, there are many options for how and where to share data and code. Researchers can do so publicly, with other researchers, or upon request (Gilmore et al., 2017). However, sharing data and code is inherently more difficult than sharing materials because it requires extra effort to transform these materials into a shareable format. Researchers will need to ensure that all variables are clearly labeled and described in such a way that reviewers or readers who are less familiar with their project can still work with the data and code. Doing so requires additional time and effort, but that work often has the added benefit of fewer statistical errors (Wicherts et al., 2011) and increased citation counts (Piwowar et al., 2007).

Like open materials, different projects have different implications for sharing; therefore, researchers who engage in this open practice need to assess the appropriate level of and venue for sharing for their work. Sharing data and code may not be feasible or even recommended for 
OPEN SCIENCE IN PSYCHOLOGY AND LAW RESEARCH 20

every project. Researchers need to account for ethical, legal, and practical considerations when deciding the extent to which they make their research products publicly available. They should ensure that they have approval to do so through their institutional review boards and consent from participants if applicable. In fact, for those working with sensitive information (e.g., institutional data from correctional or forensic facilities), researchers may wish to collaborate with ethics review boards on a detailed data sharing plan to ensure privacy (El Emam et al., 2015). There are also special considerations for those who have access to the open data and code. If researchers intend to conduct secondary analyses on open data, they should do so carefully in recognition of issues such as data ownership, alpha inflation, and confirmation biases (West, 2016).

\section{Open Access Publishing}

Another open science practice is open access publishing, which involves researchers providing some form of unrestricted access to their scholarly work. Open access publishing is an alternative to the traditional subscription-based model of academic publishing, which generally puts journal articles behind paywalls. It can take on many forms, including the sharing of manuscripts before they go through the formal peer review process (otherwise known as posting "preprints") or publishing manuscripts in an open access format or open access journal. Some journals designate certain articles as open access, allow researchers to pay an additional fee to make their article open access, or make every article in their publication open access by default. Open access publishing practices vary considerably between journals.

Similar to other open science practices, open access publishing is becoming increasingly common (Laakso et al., 2011), with many journals making all (e.g., PLOS One) or some of their articles (e.g., Law and Human Behavior, Legal and Criminological Psychology) publicly 
OPEN SCIENCE IN PSYCHOLOGY AND LAW RESEARCH 21

available and many researchers archiving their articles in preprint servers (e.g., PsyArXiv) or social networks (e.g., ResearchGate). There are many arguments advancing the open access publishing movement. Some focus on the idea that science is itself a collaborative venture and that open sharing among scientists would lead to faster, more efficient, and better scientific progress (Nosek \& Bar-Anan, 2012). Indeed, open access articles tend to have a higher impact, as reflected in higher citation counts, than their traditional counterparts (Tennant et al., 2016). We see the same benefit with preprints, with articles preceded by a preprint receiving more views and higher citation counts than articles with no preprint (Fu \& Hughey, 2019). Other arguments focus on the fact that much of scientific research is funded by taxpayers and therefore should be accessible to taxpayers without them having to pay a fee for the article or for a subscription to a journal that did not itself fund the work (Björk, 2017; Parker, 2013). Some take a broad moral position that scientific knowledge should be accessible to all who can benefit from it (Masuzzo, 2017). Regardless of which argument is leading the movement, many express optimism that open access will soon become the norm for scientific publishing (e.g., Joseph, 2013; Lewis, 2012).

Practically, open access publishing appears fairly straightforward. Authors can submit their manuscripts into a preprint server, such as PsyArXiv, prior to sending it through the peer review process. Doing so can allow the researchers to have earlier dissemination of their work as well as get earlier feedback that they may choose to incorporate before sending it to a journal for submission. These preprints can be timestamped and accompanied with digital object identifiers (DOIs) so that the work can be built upon and/or cited without authors fearing that their work will be "scooped" by those who see the pre-publication manuscript. Researchers who wish to 
OPEN SCIENCE IN PSYCHOLOGY AND LAW RESEARCH 22

publish their manuscript as open access can either seek out a fully open access journal or find a journal that allows for open access articles.

Open access publishing comes with some challenges and complications still to be addressed. Many journals will not consider papers that have been publicly disseminated elsewhere. For some journals, preprints are considered public dissemination, so authors planning to submit their work should be mindful of journal policies on preprints (see Table 2 for an online resource for preprint policies of different journals). Preprints also risk compromising masked review if scholars come across the preprint of a paper they have been asked to review (this happened with a preprint for two authors of this chapter, in fact). Delays in review, retraction of the preprint from servers, and rejection from the journal are all possible avenues depending on how reviewers and journals respond in those situations. There is also concern about how well people in and out of the scientific community appreciate the "in progress" status of many papers on preprint servers (Cook et al., 2019), an issue particularly apparent in the wildly variable media coverage of preprints for COVID-19 research (Fleerackers et al., 2021). Dissemination of papers before they have been vetted through peer review might risk publicizing findings that peer review later uncovers to be misleading, incomplete, or downright wrong. One question that arises from these concerns is not if preprints should be publicly shared, but rather when they should be shared. Lastly, there are considerable inequities in terms of which scientists have means to publish open access in journals. Journals that offer open access publishing may charge a substantial fee to do so; therefore, those who wish to publish their article in an open access format may need to plan in advance to ensure they have the necessary funding to do so. 
OPEN SCIENCE IN PSYCHOLOGY AND LAW RESEARCH 23

Irreproducibility, replication failures, false-positive errors, and QRPs have catalyzed the open science movement in psychology and other disciplines. The field of psychology and law is adapting to these changes as well. A quick glance through recent articles in the field's top peerreviewed journals and a stroll through an American Psychology-Law Society poster session will reveal a number of open science badges or links to open materials and data.

Yet we do not know the degree to which the issues that brought about the open science movement specifically affect our field because psychology and law research on this topic is extremely sparse (c.f., special issue of direct replications to be published in Legal and Criminological Psychology, Spring 2023). Irvine and colleagues (2018) took a critical first step by attempting replications of three experiments on issues relevant to civil litigation (apologies, framing effects of litigant roles, and valuations of physical and financial harms). They characterized the results of the replications as "partially successful" (p. 340) and pointed to contextual sensitivity of the original studies (e.g., one involved a bicyclist/pedestrian accident on path in a park, another used saving the dolphins as a salient exemplar of environmental advocacy) as one potential explanation for the observed differences. With respect to QRPs, a survey by John and colleagues (2012) included a small subsample $(n=16)$ of forensic psychologists, $28 \%$ of whom had engaged in at least one of these practices in their own research. A considerably higher percentage (87\%) of respondents from the related field of criminology admitted to using QRPs as well (Chin et al., 2021).

These preliminary data suggest that the current state of psychology and law is similar to other disciplines: replicability is imperfect and QRPs are common. Whatever the case may prove to be based on future studies, there is no time to waste with so much work needed to improve psychology and law research. 
OPEN SCIENCE IN PSYCHOLOGY AND LAW RESEARCH 24

\section{Implementing Change When Conducting and Evaluating Research}

Research assessing the replicability of psychology and law research is necessary and ongoing. However, adopting open science practices should improve the validity of the field's scientific findings. Our advice is to think big but to start small by creating a free account on Open Science Framework (osf.io) or AsPredicted (aspredicted.org). These websites provide resources to facilitate the process, including pre-registration templates. In fact, AsPredicted even has a "Just trying it out; make this pre-registration self-destroy in 24 hours" option complete with a cartoon-style bomb emoji (see, isn't open science fun?). After familiarizing yourself with the websites, you can then use them to begin engaging in open science. When designing your next study, choose one of the templates and use it to preregister your hypotheses, method, and data analytic plan. After collecting data, keep careful records of the analyses, including confirmatory and exploratory analyses, as well as any deviations from the original plan. Have a colleague or lab member use your data and follow your analysis plan to determine the reproducibility of your results. Better yet, have a colleague or lab member analyze simulated data to determine if you should modify your analysis plan before preregistration. Be thorough and transparent when drafting your manuscript by implementing the " 21 word solution" to describe your methodology: "We report how we determined our sample size, all data exclusions (if any), all manipulations, and all measures in the study" (Simmons et al., 2012). Archive your deidentified data file, code, and results on a public repository and be willing to extend your work by replicating and collaborating with others. Be open about intentions to reform and admit errors - doing so can even increase public perceptions of researcher trustworthiness and credibility (Altenmüller et al., 2021). 
Implementing open science practices should not be limited to one's own research

program. When reviewing manuscripts or grant proposals, researchers should demand the high

level of rigor and transparency that they aspire to their own work. For example, if a manuscript is

light or unclear on methodological details, consider including this standard request from the

Center for Open Science:

I request that the authors add a statement to the paper confirming whether, for all experiments, they have reported all measures, conditions, data exclusions, and how they determined their sample sizes. The authors should, of course, add any additional text to ensure the statement is accurate. This is the standard reviewer disclosure request endorsed by the Center for Open Science [see also http://osf.io/hadz3].

Reviewers must also recalibrate their expectations for "pretty" data that tell a "neat" story. Restricting researcher degrees of freedom, QRPs, and HARKing almost certainly will result in messier, but more valid, findings. This transition will require tolerance and patience for everyone involved. Reviewers should not be afraid to ask authors to demonstrate that results do not hinge on arbitrary analytic decisions and to request replications if authors' data collection or analysis justifications are not compelling (Simmons et al., 2011).

\section{Training the Next Generation}

Students can also benefit from incorporating open science into university courses.

Beginning in introductory courses, professors can share basic information about the reproducibility crisis and open science practices, which can then be expanded upon in more advanced courses. Several modules, syllabi, and teaching resources exist for use with undergraduates (see Table 2). Even a brief hour-long lecture teaching students about these issues can increase their comprehension without damaging their overall perceptions of the field (Chopik et al., 2018). Research methods, thesis, or capstone courses offer a unique opportunity to train students firsthand in open science practices by conducting replication studies (Frank \& Saxe, 
2012; Hawkins et al., 2018). With proper supervision, students could contribute to large replication databases that could provide immense benefit to the field (Grahe et al., 2012), while also increasing students' interest and enjoyment in the research process. Graduate methods courses could also take advantage of similar processes to collect replication data (Hawkins et al., 2018) and to teach open science practices (Tackett et al., 2020).

Psychology and law researchers must also be mindful that their laboratories house the next generation of psychological scientists. What we say and do undoubtedly will affect junior lab members (Krishna \& Peter, 2018). Senior researchers tend to support QRPs more and open science less than their students (Chin et al., 2021). Knowledge of mentor engagement in QRPs significantly predicts students' self-reported QRPs (Swift et al., 2020) and beliefs that QRPs are normative or necessary for career success are associated with increased acceptability of QRPs (Sacco et al., 2018). The message from these data is clear: old dogs must be willing to learn new tricks. Otherwise, we risk passing on outdated and subpar research skills to the next generation of psychological scientists. Researchers can make open science practices like preregistration and preprints standard operating laboratory procedures to increase students' familiarity and normalize usage (Kathawalla et al., 2021). Creating shared lab documents and codebooks to standardize note taking and reporting data collection issues can further promote research transparency and facilitate data sharing (see Table 2 for a list of resources). Providing students a variety of opportunities to practice open research will facilitate their development as junior scientists, ensuring the field becomes even more transparent and accessible as they progress in their own careers.

\section{Open Science in Applied Settings}


\begin{tabular}{ll}
\hline OPEN SCIENCE IN PSYCHOLOGY AND LAW RESEARCH & 27
\end{tabular}

Psychology and law researchers must also consider the downstream effects of open science on their work in applied settings. One of the primary conduits for psychological science into the legal system is expert testimony. Psychology experts testify on an array of issues relevant to civil and criminal cases, including dangerousness, competency, intellectual and social functioning, eyewitness identification, confessions, and witness suggestibility. Adopting open science practices may enable psychological research to better meet the Daubert admissibility standards of relevant and valid (or "reliable" using the Court's terminology) expert evidence (Chin et al., 2019). A review of 364 psychological assessment tools forensic psychologists commonly use in legal cases found that only $25 \%$ had generally favorable evaluations of quality (Neal et al., 2019). Transparent and accessible research would offer a clearer understanding of the work needed to bring the remaining $75 \%$ of tools to acceptable levels of reliability and validity for courts. Moreover, peer-reviewed research that is published with inflated rates of false-positive errors associated with researcher degrees of freedom and QRPs could lead judges to erroneously admit flawed research (Hu et al., 2018). False-positive errors also skew and distort estimations of a methodology's error rate. Open science practices that decrease false-positives and increase nonsignificant results in the published literature will more accurately reflect the true state of psychological science and should result in more effective admissibility decisions by judges (Chin et al., 2020). In essence, increased transparency and accessibility in the field psychology and law can show how robust its tools and research actually are and simultaneously set up opportunities to improve them.

Open science practices can also benefit other actors within the criminal justice and legal systems. More accurately evaluating the strength of scientific evidence in a case may enhance the ability of investigators to determine whether to follow other avenues in an investigation or 
attorneys to recommend their clients take a plea versus challenge the evidence in court (Chin et al., 2020). Similarly, a recent Pew Research Center (2019) survey found 54\% of the respondents indicated they would have greater trust in scientific findings if open data practices were used. Although research has not yet explored the impact of open science practices in a field or by a particular expert witness on jurors' perceptions of scientific evidence, this finding suggests that adoption of open science practices may engender greater trust in experts and make them more effective on the witness stand.

All of this is not to say that adopting open science practices will be an easy feat for psychology and law. Our field has unique limitations that must be taken into account. For example, we often work with sensitive populations, such as individuals in prison settings, children, and survivors of crime. These populations present valuable research opportunities but also present a potential obstacle for publicly sharing data. Although there are preventive steps researchers can take to protect this sensitive data, there remains a risk of reidentification by those who share intimate knowledge of the events being studied (Campbell et al., 2019; Finkel et al., 2015; Ross et al., 2018). However, these issues are not insurmountable, and scholars have described best practices for the ethical sharing of sensitive data (e.g., Campbell et al., 2019; Gilmore et al., 2018; Meyer, 2018). Repositories can also provide protective access for data that can facilitate sharing with qualified personnel (Chin \& Zeiler, 2021; Schumann et al., 2019). Some of these practices may be acceptable to organizations that typically restrict data sharing. Even when data are not shareable, this does not necessarily stop researchers from preregistering hypotheses or sharing materials. Open science is not an "all-or-nothing" endeavor-researchers can engage in one open science practice even if another is not available to them. Certainly something is better than nothing. 


\section{Conclusion}

Valid science in psychology and law matters because our contributions as researchers and practitioners have great potential to meaningfully influence - in positive and negative ways — the lives of people involved in the legal and criminal justice systems. Judges, attorneys, police, jurors, victims, plaintiffs, defendants, corrections officers, and prisoners rely on us and the work we do. We owe it to these individuals and ourselves to improve psychology and law research by adopting more transparent and accessible practices. Doing so will help ensure our conclusions are sound and lead to recommendations that promote justice for all. 


\section{References}

Allen, C., \& Mehler, D. M. A. (2019). Open science challenges, benefits and tips in early career and beyond. PLOS Biology, 17(12), Article e3000246. https://doi.org/10.1371/journal.pbio.3000246

Altenmüller, M. S., Nuding, S., \& Gollwitzer, M. (2021). No harm in being self-corrective: Selfcriticism and reform intentions increase researchers' epistemic trustworthiness and credibility in the eyes of the public. Public Understanding of Science. Advance online publication. https://doi.org/10.1177/09636625211022181

Anderson, M. S., Martinson, B. C., \& De Vries, R. (2007). Normative dissonance in science: Results from a national survey of U.S. scientists. Journal of Empirical Research on Human Research Ethics, 2(4), 3-14. https://doi.org/10.1525/jer.2007.2.4.3

Arabito, S., \& Pitrelli, N. (2015). Open science training and education: Challenges and difficulties on the researchers' side and in public engagement. Journal of Science Communication, 14(4), Article C01_en. https://doi.org/10.22323/2.14040301

Artner, R., Verliefde, T., Steegen, S., Gomes, S., Traets, F., Tuerlinckx, F., \& Vanpaemel, W. (2020). The reproducibility of statistical results in psychological research: An investigation using unpublished raw data. Psychological Methods. Advance online publication. https://doi.org/10.1037/met0000365

Asendorpf, J. B., Conner, M., De Fruyt, F., De Houwer, J., Denissen, J. J. A., Fiedler, K., Fiedler, S., Funder, D. C., Kliegl, R., Nosek, B. A., Perugini, M., Roberts, B. W., Schmitt, M., van Aken, M. A. G., Weber, H., \& Wicherts, J. M. (2013). Recommendations for increasing replicability in psychology. European Journal of Personality, 27(2), 108-119. https://doi.org/10.1002/per.1919 
Bergh, D. D., Sharp, B. M., Aguinis, H., \& Li, M. (2017). Is there a credibility crisis in strategic management research? Evidence on the reproducibility of study findings. Strategic Organization, 15(3), 423-436. https://doi.org/10.1177/1476127017701076

Björk, B-C. (2017). Gold, green, and black open access. Learned Publishing, 30(2), 173-175. https://doi.org/10.1002/leap.1096

Borgerud, C., \& Borglund, E. (2020). Open research data, an archival challenge? Archival Science, 20(3), 279-302. https://doi.org/10.1007/s10502-020-09330-3

Bowman, N. D., \& Spence, P. R. (2020). Challenges and best practices associated with sharing research materials and research data for communication scholars. Communication Studies, 71(4), 708-716. https://doi.org/10.1080/10510974.2020.1799488

Cairo, A. H., Green, J. D., Forsyth, D. R., Behler, A. M. C., \& Raldiris, T. L. (2020). Gray (literature) matters: Evidence of selective hypothesis reporting in social psychological research. Personality and Social Psychology Bulletin, 46(9), 1344-1362. https://doi.org/10.1177/0146167220903896

Campbell, R., Goodman-Williams, R., \& Javorka, M. (2019). A trauma-informed approach to sexual violence research ethics and open science. Journal of Interpersonal Violence, 34(23-24), 4765-4793. https://doi.org/10.1177/0886260519871530

Chambers, C. (2019). The registered reports revolution: Lessons in cultural reform. Significance, 16(4), 23-27. https://doi.org/10.1111/j.1740-9713.2019.01299.x

Chambers, C. D., Feredoes, E., Muthukumaraswamy, S. D., \& Etchells, P. J. (2014). Instead of "playing the game" it is time to change the rules: Registered reports at AIMS Neuroscience and beyond. AIMS Neuroscience, 1(1), 4-17. https://doi.org/10.3934/Neuroscience.2014.1.4 
\begin{tabular}{ll}
\hline OPEN SCIENCE IN PSYCHOLOGY AND LAW RESEARCH & 32
\end{tabular}

Chambers, C. D., \& Tzavella, L. (2020). The past, present, and future of registered reports. MetaArXiv. https://doi.org/10.31222/osf.io/43298

Chin, J. M., Pickett, J. T., Vazire, S., \& Holcombe, A. O. (2021). Questionable research practices and open science in quantitative criminology. Journal of Quantitative Criminology. Advance online publication. https://doi.org/10.1007/s10940-021-09525-6

Chin, J. M., Ribeiro, G., \& Rairden, A. (2019). Open forensic science. Journal of Law and the Biosciences, 6(1), 255-288. https://doi.org/10.1093/jlb/lsz009

Chin, J. M., McFadden, R., \& Edmond, G. (2020). Forensic science needs registered reports. Forensic Science International: Synergy, 2, 41-45. https://doi.org/10.1016/j.fsisyn.2019.10.005

Chin, J. M., \& Zeiler, K. (2021). Replicability in empirical legal research. Annual Review of Law and Social Science. Advance online publication. https://doi.org/10.1146/annurev$\underline{\text { lawsocsci-121620-085055 }}$

Chopik, W. J., Bremner, R. H., Defever, A. M., \& Keller, V. N. (2018). How (and whether) to teach undergraduates about the replication crisis in psychological science. Teaching of Psychology, 45(2), 158-163. https://doi.org/10.1177/0098628318762900

Cohen, J. (1962). The statistical power of abnormal-social psychological research: A review. The Journal of Abnormal and Social Psychology, 65(3), 145-153. https://doi.org/10.1037/h0045186

Cook, B. G., Lloyd, J. W., \& Therrien, W. J. (2019). Open science in the field of emotional and behavioral disorders. Education and Treatment of Children, 42(4), 579-600. https://doi.org/10.1353/etc.2019.0027 
OPEN SCIENCE IN PSYCHOLOGY AND LAW RESEARCH 33

Dreber, A., Pfeiffer, T., Almenberg, J., Isaksson, S., Wilson, B., Chen, Y., Nosek, B. A., \& Johannesson, M. (2015). Using prediction markets to estimate the reproducibility of scientific research. Proceedings of the National Academy of Sciences, 112(50), 1534315347. https://doi.org/10.1073/pnas.1516179112

Eich, E. (2014). Business not as usual. Psychological Science, 25(1), 3-6. https://doi.org/10.1177/0956797613512465

El Emam, K., Rodgers, S., \& Malin, B. (2015). Anonymising and sharing individual patient data. BMJ, 350, Article h1139. https://doi.org/10.1136\%2Fbmj.h1139

Finkel, E. J., Eastwick, P. W., \& Reis, H. T. (2015). Best research practices in psychology: Illustrating epistemological and pragmatic considerations with the case of relationship science. Journal of Personality and Social Psychology, 108(2), 275-297. https://doi.org/10.1037/pspi0000007

Fleerackers, A., Riedlinger, M., Moorhead, L., Ahmed, R., \& Alperin, J. P. (2021). Communicating scientific uncertainty in an age of COVID-19: An investigation into the use of preprints by digital media outlets. Health Communication. Advance online publication. https://doi.org/10.1080/10410236.2020.1864892

Franco, A., Malhotra, N., \& Simonovits, G. (2016). Underreporting in psychology experiments evidence from a study registry. Social Psychological and Personality Science, 7(1), 8-12. https://doi.org/10.1177/1948550615598377

Frank, M. F., \& Saxe, R. (2012). Teaching replication. Perspectives on Psychological Science, 7(6), 600-604. https://doi.org/10.1177/1745691612460686 
Fu, D. Y., \& Hughey, J. J. (2019). Meta-research: Releasing a preprint is associated with more attention and citations for the peer-reviewed article. eLife, 8, Article e52646. https://doi.org/10.7554/eLife.52646

Gilmore, R. O., Kennedy, J. L., \& Adolph, K. E. (2018). Practical solutions for sharing data and materials from psychological research. Advances in Methods and Practices in Psychological Science, 1(1), 121-130. https://doi.org/10.1177/2515245917746500

Goldin-Meadow, S. (2016, September). Why preregistration makes me nervous. APS Observer. https://www.psychologicalscience.org/observer/why-preregistration-makes-me-nervous.

Gordon, M., Viganola, D., Dreber, A., Johannesson, M., \& Pfeiffer, T. (2021) Predicting replicability-Analysis of survey and prediction market data from large-scale forecasting projects. PLOS One, 16(4), Article e0248780. https://doi.org/10.1371/journal.pone.0248780

Götz, F. M., Gosling, S. D., Rentfrow, P. J. (2021). Small effects: The indispensable foundation for a cumulative psychological science. Perspectives on Psychological Science. Advance online publication. https://doi.org/10.1177/1745691620984483

Grahe, J. E., Reifman, A., Hermann, A. D., Walker, M., Oleson, K. C., Nario-Redmond, M., \& Wiebe, R. P. (2012). Harnessing the undiscovered resource of student research projects. Perspectives on Psychological Science, 7(6), 605-607. https://doi.org/10.1177/1745691612459057

Hardwicke, T. E., Bohn, M., MacDonald, K., Hembacher, E., Nuijten, M. B., Peloquin, B. N., deMayo, B. E., Long, B., Yoon, E. J., \& Frank, M. C. (2021). Analytic reproducibility in articles receiving open data badges at the journal Psychological Science: An 
OPEN SCIENCE IN PSYCHOLOGY AND LAW RESEARCH 35

observational study. Royal Society Open Science, 8(1), Article 201494.

https://doi.org/10.1098/rsos.201494

Hardwicke, T. E., Mathur, M. B., MacDonald, K., Nilsonne, G., Banks, G. C., Kidwell, M. C., Mohr, A. H., Clayton, E., Yoon, E. J., Tessler, M. H., Lenne, R. L., Altman, S., Long, B., \& Frank, M. C. (2018). Data availability, reusability, and analytic reproducibility: Evaluating the impact of a mandatory open data policy at the journal Cognition. Royal Society Open Science, 5(8), Article 180448. https://doi.org/10.1098/rsos.180448

Hawkins, R. X. D., Smith, E. N., Au, C., Arias, J. M., Catapano, R., Hermann, E., Keil, M., Lampinen, A., Raposo, S., Reynolds, J., Salehi, S., Salloum, J., Tan, J., \& Frank, M. C. (2018). Improving the replicability of psychological science through pedagogy. Advances in Methods and Practices in Psychological Science, 1(1), 7-18. https://doi.org/10.1177/2515245917740427

Hu, C-P., Jiang, X., Jeffrey, R., \& Zuo, X-N. (2018). Open science as a better gatekeeper for science and society: A perspective from neurolaw. Science Bulletin, 63(23), 1529-1531. https://doi.org/10.1016/j.scib.2018.11.015

Hummer, L. T., Singleton Thorn, F., Nosek, B. A., \& Errington, T. M. (2017). Evaluating registered reports: A naturalistic comparative study of article impact. OSF Preprints. https://doi.org/10.31219/osf.io/5y8w7

Ioannidis, J. P. A. (2005). Why most published research findings are false. PLOS Medicine, 2(8), Article e124. https://doi.org/10.1371/journal.pmed.0020124

Irvine, K., Hoffman, D. A., \& Wilkinson-Ryan, T. (2018). Law and psychology grow up, goes online, and replicates. Journal of Empirical Legal Studies, 15(2), 320-355. https://doi.org/10.1111/jels. 12180 
John, L. K., Loewenstein, G., Prelec, D. (2012). Measuring the prevalence of questionable research practices with incentives for truth telling. Psychological Science, 23(5), 524532. https://doi.org/10.1177/0956797611430953

Jonas, K. J., \& Cesario, J. (2015). How can preregistration contribute to research in our field. Comprehensive Results in Social Psychology, 1(1-3), 1-7. https://doi.org/10.1080/23743603.2015.1070611

Joseph, H. (2013). The open access movement grows up: Taking stock of a revolution. PLoS Biology, 11(10), Article e1001686. https://doi.org/10.1371/journal.pbio.1001686

Kaplan, R. M., \& Irvine, V. L. (2015). Likelihood of null effects of large NHLBI clinical trials has increased over time. PLoS One, 10(8), Article e0132382. https://doi.org/10.1371/journal.pone.0132382

Kathawalla, U-K., Silverstein, P., \& Syed, M. (2021). Easing into open science: A guide for graduate students and their advisors. Collabra: Psychology, 7(1), Article 18684. https://doi.org/10.1525/collabra.18684

Kerr, N. L. (1998). HARKing: hypothesizing after the results are known. Personality and Social Psychology Review, 2(3), 196-217. https://doi.org/10.1207/s15327957pspr0203 4

Kidwell, M. C., Lazarević, L. B., Baranski, E., Hardwicke, T. E., Piechowski, S., Falkenberg, LS., Kennett, C., Slowik, A., Sonnleitner, C., Hess-Holden, C., Errington, T. M., Fiedler, S., \& Nosek, B. A. (2016). Badges to acknowledge open practices: A simple low-cost effective method for increasing transparency. PLOS Biology, 14(5), Article e1002456. https://doi.org/10.1371/journal.pbio.1002456

Klein, O., Hardwicke, T. E., Aust, F., Breuer, J., Danielsson, H., Mohr, A. H., IJzerman, H., Nilsonne, G., Vanpaemel, W., \& Frank, M. C. (2018). A practical guide for transparency 
in psychological science. Collabra: Psychology, 4(1), Article 20.

https://doi.org/10.1525/collabra.158

Krishna, A., \& Peter, S. M. (2018). Questionable research practices in student final theses Prevalence, attitudes, and the role of the supervisors' perceived attitudes. PLoS One, 13(8), Article e0203470. https://doi.org/10.1371/journal.Pone.0203470

Laakso, M., Welling, P., Bukvova, H., Nyman, L., Björk, B-C., Hedlund, T. (2011). The development of open access journal publishing from 1993 to 2009. PLoS One, 6(6), Article e20961. https://doi.org/10.1371/journal.pone.0020961

Lamb, M. E., Steblay, N. K., \& Neal, T. M. S. (2021). Psychology, Public Policy, and Law adopts further open science practices and refreshes its commitment to generalizable empirical research. Psychology, Public Policy, and Law, 27(3), 293-294. http://dx.doi.org/10.1037/law0000318

Ledgerwood, A., Hudson, S. T. J., Lewis, N.A., Jr., Maddox, K. B., Pickett, C. L., Remedios, J.D., Cheryan, S., Diekman, A. B., Dutra, N. B., Goh, J. X., Goodwin, S. A., Munakata, Y., Navarro, D. J., Onyeador, I. N., Srivastava, S., \& Wilkins, C. L. (in press). The pandemic as a portal: Reimagining psychological science as truly open and inclusive. Perspectives on Psychological Science.

Lewis, D. W. (2012). The inevitability of open access. College and Research Libraries, 73(5), 493-505. https://doi.org/10.5860/crl-299

Lindsay, D. S. (2015). Replication in Psychological Science. Psychological Science, 26(12), 1827-1832. https://doi.org/10.1177/0956797615616374

Lindsay, D. S. (2017). Sharing data and materials in Psychological Science. Psychological Science, 28(6), 699-702. https://doi.org/10.1177/0956797617704015 
Lindsay, D. S., Simons, D. J., \& Lilienfeld, S. O. (2016, November 30). Research preregistration 101. APS Observer. https://www.psychologicalscience.org/observer/researchpreregistration-101

Lovakov, A., \& Agadullina, E. R. (2021). Empirically derived guidelines for effect size interpretation in social psychology. European Journal of Social Psychology. Advance online publication. https://doi.org/10.1002/ejsp.2752

MacWhinney, B., \& Snow, C. (1985). The child language data exchange system. Journal of child language, 12(2), 271-295. https://doi.org/10.1017/S0305000900006449

Masuzzo, P., \& Martens, L. (2017). Do you speak open science? Resources and tips to learn the language. PeerJ Preprints 5:e2689v1. https://doi.org/10.7287/peerj.preprints.2689v1

Maxwell, S. E., Lau, M. Y., \& Howard, G. S. (2015). Is psychology suffering from a replication crisis? What does "failure to replicate" really mean? American Psychologist, 70(6), 487498. https://doi.org/10.1037/a0039400

McAuliff, B. D., Hunt, J. S., Levett, L. M., Zelechoski, A. D., Scherr, K. C., \& DeMatteo, D. (2019). Taking the next steps: Promoting open science and expanding diversity in Law and Human Behavior. Law and Human Behavior, 43(1), 1-8. https://doi.org/10.1037/lhb0000322

Mayo-Wilson, E., Grant, S., Supplee, L., Kianersi, S, Amin, A., DeHaven, A., \& Mellor, D. (2021). Evaluating implementation of the Transparency and Openness Promotion (TOP) guidelines: the TRUST process for rating journal policies, procedures, and practices. Research Integrity and Peer Review,6(9), 1-11. https://doi.org/10.1186/s41073-021$\underline{00112-8}$ 
Meyer, M. N. (2018). Practical tips for ethical data sharing. Advances in Methods and Practices in Psychological Science, 1(1), 131-144. https://doi.org/10.1177/2515245917747656

Motyl, M., Demos, A. P., Carsel, T. S., Hanson, B. E., Melton, Z. J., Mueller, A. B., Prims, J. P., Sun, J., Washburn, A. N., Wong, K. M., Yantis, C., \& Skitka, L. J. (2017). The state of social and personality science: Rotten to the core, not so bad, getting better, or getting worse? Journal of Personality and Social Psychology, 113(1), 34-58. https://doi.org/10.1037/pspa0000084

Neal, T. M. S., Slobogin, C., Saks, M. J., Faigman, D. L., \& Geisinger, K. F. (2019).

Psychological assessments in legal contexts: Are courts keeping "junk science" out of the courtroom? Psychological Science in the Public Interest, 20(3), 135-164. https://doi.org/10.1177/1529100619888860

Nelson, L. D., Simmons, J., \& Simonsohn, U. (2018). Psychology’s renaissance. Annual Review of Psychology, 69, 511-534. https://doi.org/10.1146/annurev-psych-122216-011836

Neuschatz, J. S. (2020). Editorial. Psychology, Crime, and Law, 26(3), 207. https://doi.org/10.1080/1068316X.2020.1729968

Nosek, B. A., \& Bar-Anan, Y. (2012). Scientific utopia: I. Opening scientific communication. Psychological Inquiry, 23(3), 217-243. https://doi.org/10.1080/1047840X.2012.692215

Nosek, B. A., \& Lakens, D. (2014). Registered reports: A method to increase the credibility of published results. Social Psychology, 45(3), 137-141. https://doi.org/10.1027/1864$\underline{9335 / a 000192}$

Nosek, B. A., \& Lindsay, D. S. (2018, February 28). Preregistration becoming the norm in psychological science. APS Observer. 
OPEN SCIENCE IN PSYCHOLOGY AND LAW RESEARCH 40

https://www.psychologicalscience.org/observer/preregistration-becoming-the-norm-in-

psychological-science

Nosek, B. A., Spies, J. R., \& Motyl, M. (2012). Scientific utopia II. Restructuring incentives and practices to promote truth over publishability. Perspectives on Psychological Science, 7(6), 615-631. https://doi.org/10.1177/1745691612459058

Nosek, B. A., Alter, G., Banks, G. C., Borsboom, D., Bowman, S. D., Breckler, S. J., Buck, S., Chambers, C. D., Chin, G., Christensen, G., Contestabile, M., Dafoe, A., Eich, E., Freese, J., Glennerster, R., Goroff, D., Green, D. P., Hesse, B., Humphreys, M., .. Yarkoni, T. (2015). Promoting an open research culture. Science, 348(6242), 1422-1425. https://doi.org/10.1126/science.aab2374

Nosek, B. A., Ebersole, C. R., DeHaven, A. C., \& Mellor, D. T. (2018). The preregistration revolution. Proceedings of the National Academy of Sciences, 115(11), 2600-2606. https://doi.org/10.1073/pnas.1708274114

Nosek, B. A., Hardwicke, T. E., Moshontz, H., Allard, A., Corker, K. S., Dreber, A., Fidler, F., Hilgard, J., Kline Struhl, M., Nuijten, M., Rohrer, J., Romero, F., Scheel, A., Scherer, L., Schönbrodt, F., \& Vazire, S. (2021). Replicability, robustness, and reproducibility in psychological science. PsyArXiv. https://doi.org/10.31234/osf.io/ksfvq

Open Science Collaboration. (2015). Estimating the reproducibility of psychological science. Science, 349(6251), 1-8. https://doi.org/10.1126/science.aac4716

Parker, M. (2013). The ethics of open access publishing. BMC Medical Ethics, 14, Article 16. https://doi.org/10.1186/1472-6939-14-16 
Pashler, H., \& Wagenmakers, E-J. (2012). Editors' introduction to the special section on replicability in psychological science: A crisis of confidence? Perspectives on Psychological Science, 7(6), 528-530. https://doi.org/10.1177/1745691612465253

Pew Research Center (2019). Trust and mistrust in Americans' views of scientific experts. https://www.pewresearch.org/science/2019/08/02/trust-and-mistrust-in-americans-viewsof-scientific-experts/

Piwowar, H. A., Day, R. S., \& Fridsma, D. B. (2007). Sharing detailed research data is associated with increased citation rate. PLoS One, 2(3), Article e308. https://doi.org/10.1371/journal.pone.0000308

Roberts, S. O., Bareket-Shavit, C., Dollins, F. A., Goldie, P. D., \& Mortenson, E. (2020). Racial inequality in psychological research: Trends of the past and recommendations for the future. Perspectives on Psychological Science, 15(6), 1295-1309. https://doi.org/10.1177/1745691620927709

Ross, M. W., Iguchi, M. Y., \& Panicker, S. (2018). Ethical aspects of data sharing and research participant protections. American Psychologist, 73(2), 138-145. $\underline{\text { https://doi.org/10.1037/amp0000240 }}$

Sacco, D. F., Bruton, S. V., \& Brown, M. (2018). In defense of the questionable: Defining the basis of research scientists' engagement in questionable research practices. Journal of Empirical Research on Human Research Ethics, 13(1), 101-110. https://doi.org/10.1177/1556264617743834

Scheel, A. M., Schijen, M. R. M. J., \& Lakens, D. (2021). An excess of positive results: Comparing the standard psychology literature with registered reports. Advances in 
Methods and Practices in Psychological Science, 4(2), 1-12. https://doi.org/10.1177/25152459211007467

Schneider, J., Rosman, T., Kelava, A., \& Merk, S. (2020). (Re)building trust? Journals'open science badges influence trust in scientists. PsychArchives. https://doi.org/10.23668/PSYCHARCHIVES.3364

Schumann, S., van der Vegt, I., Gill, P., \& Schuurman, B. (2019). Towards open and reproducible terrorism studies: Current trends and next steps. Perspectives on Terrorism, $13(5), 61-73$.

Schwarz, N. (1999). Self-reports: How the questions shape the answers. American Psychologist, 54(2), 93-105. https://doi.org/10.1037/0003-066X.54.2.93

Sedlmeier, P., \& Gigerenzer, G. (1989). Do studies of statistical power have an effect on the power of studies? Psychological Bulletin, 105(2), 309-316. https://doi.org/10.1037/0033$\underline{2909.105 .2 .309}$

Simmons, J. P., Nelson L. D., \& Simonsohn, U. (2011). False-positive psychology: Undisclosed flexibility in data collection and analysis allows presenting anything as significant. Psychological Science, 22(11), 1359-1366. https://doi.org/10.1177/0956797611417632

Simmons, J. P., Nelson, L. D., \& Simonsohn, U. (2012). A 21 word solution. The Official Newsletter of the Society for Personality and Social Psychology, 26(2), 4-7. https://doi.org/10.2139/ssrn.2160588

Spellman, B. A., Gilbert, E. A., \& Corker, K. S. (2018). Open science. In J. T. Wixted \& E.-J. Wagenmakers (Eds.), Stevens' handbook of experimental psychology and cognitive neuroscience, methodology (4th ed., Vol. 5, pp. 729-775). John Wiley \& Sons. https://doi.org/10.1002/9781119170174.epcn519 
OPEN SCIENCE IN PSYCHOLOGY AND LAW RESEARCH 43

Strack, F. (1992). "Order effects” in survey research: Activation and information functions of preceding questions. In N. Schwarz \& S. Sudman (Eds.), Context effects in social and psychological research. Springer-Verlag. https://doi.org/10.1007/978-1-4612-2848-6 3

Swaen, G. G., Teggeler, O., \& van Amelsvoort, L. G. (2001). False positive outcomes and design characteristics in occupational cancer epidemiology studies. International Journal of Epidemiology, 30(5), 948-954. https://doi.org/10.1093/ije/30.5.948

Swift, J. K., Christopherson, C. D., Bird, M. O., Zöld, A., \& Goode, J. (2020). Questionable research practices among faculty and students in APA-accredited clinical and counseling psychology doctoral programs. Training and Education in Professional Psychology. Advance online publication. https://doi.org/10.1037/tep0000322

Tackett, J. L., Brandes, C. M., Dworak, E. M., \& Shields, A. N. (2020). Bringing the (pre)registration revolution to graduate training. Canadian Psychology/Psychologie canadienne, 61(4), 299-309. https://doi.org/10.1037/cap0000221

Tackett, J. L., Brandes, C. M., King, K. M., \& Markon, K. E. (2019). Psychology’s replication crisis and clinical psychological science. Annual Review of Clinical Psychology, 15(1), 579-604. https://doi.org/10.1146/annurev-clinpsy-050718-095710

Tennant, J. P., Waldner, F., Jacques, D. C., Masuzzo, P., Collister, L. B., \& Hartgerink, C. H. J. (2016). The academic, economic and societal impacts of open access: An evidence-based review. F1000Research, 5, Article 632. https://doi.org/10.12688/f1000research.8460.3

Towse, A. S., Ellis, D. A., \& Towse, J. N. (2021). Making data meaningful: Guidelines for good quality open data, The Journal of Social Psychology, 161(4), 395-402. https://doi.org/10.1080/00224545.2021.1938811 
Tversky, A., \& Kahneman, D. (1986). Rational choice and the framing of decisions. The Journal of Business, 59(4), S251-S278. http://www.jstor.org/stable/2352759

Valentine, J. C., Biglan, A., Boruch, R. F., Castro, F. G., Collins, L. M., Flay, B. R., Kellam, S., Mościcki, E. K., \& Schinke, S. P. (2011). Replication in prevention science. Prevention Science: The Official Journal of the Society for Prevention Research, 12(2), 103-117. https://doi.org/10.1007/s11121-011-0217-6

van 't Veer, A. E., \& Giner-Sorolla, R. (2016). Pre-registration in social psychology-A discussion and suggested template. Journal of Experimental Social Psychology, 67, 2-12. https://doi.org/10.1016/j.jesp.2016.03.004

Vazire, S. (2017). Quality uncertainty erodes trust in science. Collabra: Psychology, 3(1), Article

\section{1. https://doi.org/10.1525/collabra.74}

Vazire, S. (2018). Implications of the credibility revolution for productivity, creativity, and progress. Perspectives on Psychological Science, 13(4), 411-417. https://doi.org/10.1177/1745691617751884

West, R. (2016). Data and statistical commands should be routinely disclosed in order to promote greater transparency and accountability in clinical and behavioral research. Journal of Clinical Epidemiology, 70, P254-P255. https://doi.org/10.1016/j.jclinepi.2015.06.015

Wicherts, J. M., Bakker, M., \& Molenaar, D. (2011). Willingness to share research data is related to the strength of evidence and the quality of reporting statistical results. PLoS One, 6(11), Article e26828. https://doi.org/10.1371/journal.pone.0026828

Wilkinson, M. D., Dumontier, M., Aalbersberg, I. J., Appleton, G., Axton, M., Baak, A., Blomberg, N., Boiten, J-W., da Silva Santos, L. B., Bourne, P. E., Bouwman, J., Brookes, 
A. J., Clark, T., Crosas, M., Dillo, I., Dumon, O., Edmunds, S., Evelo, C. T., Finkers, R., ... Mons, B. (2016). The FAIR guiding principles for scientific data management and stewardship. Scientific Data, 3, Article 160018. https://doi.org/10.1038/sdata.2016.18 
Table 1

Questionable Research Practices

$\boldsymbol{P}$-hacking - Selectively reporting studies that "worked" or failing to report studies that "didn't work"

- Failing to report all of a study's conditions, dependent measures, or outcomes

- Dropping participants, observations, measures, or conditions that yielded inconvenient data

- Excluding data after examining the impact of doing so

- Filling in missing data without identifying those values as estimated

- Stopping data collection earlier than planned because results were statistically significant

- Collecting additional data or analyses because results were not statistically significant

- Rounding down $\mathrm{p}$ values (e.g., reporting that a $\mathrm{p}$ value of .054 is less than .05)

- Applying poorly motivated and post hoc data transformations

- Adding questionable covariates or dropping covariates selectively

HARKing - Presenting post hoc hypotheses as a priori hypotheses

- Presenting hypotheses known post hoc to be contradicted by the data

- Suppressing initially plausible hypotheses that failed the immediate empirical test

- Reassessing as plausible a hypothesis originally seen as quite impossible

- Advancing a new hypothesis wholly unanticipated prior to the study

- Using current results to construct post hoc hypotheses that are reported as a priori hypotheses

- Retrieving hypotheses from a post hoc literature search and reporting them as a priori hypotheses

- Failing to report a priori hypotheses that are unsupported by the current results

Note. Adapted from QRPs examined by Chin et al. (2021); John et al. (2012); Kerr (1998); Lindsay (2015); and Simmons et al. (2011). 
Table 2

Resources for Learning about and Incorporating Open Science Practices

\section{General}

Open Scholarship Knowledge Database

7 Easy Steps to Open Science (annotated bibliography)

TOP Evidence and Practice

Improving Statistical Inferences course

\section{For Research}

Open Access Policies (journals, agencies)

Badges to Acknowledge Open Practices

Preprints

PsyArXiv (psychology preprint host)

SocArXiv (social science preprint host)

Templates (\#PrettyPreprint)

Preregistration

As Predicted

Open Science Framework

Templates

Tutorials and Webinars
https://www.oercommons.org/hubs/OSKB

https://doi.org/10.31234/osf.io/cfzyx

https://osf.io/kgnva/\#Registries_90

https://coursera.org/learn/statistical-inferences

https://v2.sherpa.ac.uk/

https://osf.io/tvyxz/

https://doi.org/10.1371/journal.pbio.1002456

https://psyarxiv.com/

https://socarxiv.org/

https://osf.io/hsv6a/

https://aspredicted.org/

https://osf.io/registries

https://osf.io/qpdth/

https://osf.io/zab38/wiki/home/

https://www.cos.io/initiatives/prereg

https://help.osf.io/hc/en-us/articles/360019738834-

create-a-preregistration

https://psyarxiv.com/hvfmr/

https://help.osf.io/m/registrations/1/546603-enter-

the-preregistration-challenge

https://www.cos.io/initiatives/registered-reports

https://osf.io/8f7hy/

https://osf.io/sbr4d/

https://osf.io/jtsn4/

https://www.cos.io/initiatives/registered-reports

https://osf.io/7pekf/ 
Twitter

\section{Replication}

Replication Curation Websites

Collaborative Replications and Education Project (CREP; resources to learn about replication and collaborate on replication projects)

Many Legal Labs (replication projects for legal psychology)

Psychological Science Accelerator (lab networking for replication projects)

\section{Shared Data}

Guidelines

National Institutes of Health Policy for Data Management and Sharing

Databrary (video data library for behavioral scientists)

Talkbank (shared audio and video samples of language samples and speech transcripts)

OpenNeuro (shared brain-imaging data sets)

Study Swap (replication, shared data)

Psych-DS (in-progress project promoting database sharing practices)

Agreements/templates for permission to share identifiable data and recordings

Protected Access Repositories (for sharing sensitive data with qualified personnel)
@RegReports

http://psychfiledrawer.org

http://curatescience.org

https://osf.io/wfc6u/

manylegallabs@gmail.com

https://psysciacc.org/ https://doi.org/10.1080/00224545.2021.1938811

https://grants.nih.gov/grants/guide/notice-

files/NOT-OD-21-013.html

https://nyu.databrary.org/

http://talkbank.org

http://openneuro.org

https://osf.io/meetings/studyswap/

https://psych-ds.github.io/

http://databrary.org/about/agreement/agreement.ht $\underline{\mathrm{ml}}$

https://www.icpsr.umich.edu/icpsrweb/content/dat amanagement/confidentiality/conf-language.html

https://osf.io/tvyxz/wiki/8.\%20Approved\%20Prote cted\%20Access\%20Repositories/

https://rubenarslan.github.io/codebook/

https://libguides.library.kent.edu/spss/codebooks

\section{Data Codebooks}

Document data with codebook $\mathrm{R}$ package and Web app

SPSS 
$\mathrm{R}$

\section{Data Anonymization}

$\mathrm{R}$

Software Tool for Removing Patient Identifying Information from Clinical Documents

\section{Random Data Generators}

R synthpop

SPSS using GRD

Registry of Data Repositories

\section{For Teaching}

Student Initiative for Open Science

Syllabi

Teaching Open Science as a course

Shared syllabi for open science coursework

\section{Course Materials}

Five-week course for teaching open science practices

Best Practices Lecture and Slides

"How to Do Open Science" Textbook

Open Science Massive Open Online Community (MOOC; shared templates for teaching open science)

Replications as pedagogy https://stats.idre.ucla.edu/spss/modules/labelingand-documenting-data/

https://rubenarslan.github.io/codebook/articles/cod ebook tutorial.html https://doi.org/10.1177/2515245919838783

https://www.ukdataservice.ac.uk/managedata/legal-ethical/anonymisation/qualitative.aspx http://psychbrief.com/anonymous-data-r/ https://bookdown.org/martin_monkman/DataScien ceResources_book/anonymity-andconfidentiality.html https://academic.oup.com/jamia/article/15/5/601/7 $\underline{32612}$ https://www.synthpop.org.uk/get-started.html https://www.tqmp.org/RegularArticles/vol102/p080/p080.pdf https://www.re3data.org

$@$ StudentIOS

https://osf.io/4ekac/

https://osf.io/3dp52/

https://osf.io/vkhbt/ https://osf.io/zbwr4/

https://www.bitss.org/mooc-parent-page/

https://osf.io/mh9pe/

https://www.ucpress.edu/book/9780520296954/tra nsparent-and-reproducible-social-science-research https://github.com/OpenScienceMOOC

https://doi.org/10.1177/2515245917740427 
https://journals.sagepub.com/doi/10.1177/1745691

$\underline{612460686}$

Open Access Textbooks

OER Commons (Open Education

https://www.oercommons.org/

Resources)

Open Science Training Handbook

Noba

https://book.fosteropenscience.eu/en/

https://nobaproject.com/

\section{Organizations}

Berkeley Initiative for Transparency in the Social Sciences (BITSS)

https://www.bitss.org/

@UCBITSS

Center for Open Science (COS)

https://www.cos.io/

@OSFramework

Framework for Open and Reproducible $\quad$ https://forrt.org/

Research Training (FORRT)

Institute for Globally Distributed Open

Research and Education (IGDORE)

Project TIER

\section{mel/forttorg/}

https://igdore.org/

https://www.projecttier.org/

Society for the Improvement of

http://improvingpsych.org

Psychological Science (SIPS)

Open Psychology \& Law Science

@openpsychlaw

Note. Some resources derived from Spellman et al. (2018) and Towse et al. (2021). 